\title{
ESTUDOS SOBRE JOHN DEWEY: O ESTÁGIO EM ARTES VISUAIS NA EDUCAÇÃO INFANTIL
}

STUDIES ON JOHN DEWEY:

THE INTERNSHIP IN VISUAL ARTS IN CHILDHOOD EDUCATION

Miguel Vassali ${ }^{1}$

1 Possui graduação em Design pela Universidade do Oeste de Santa Catarina (2012). Atualmente cursa graduação em Artes Visuais - Licenciatura e mestrado em Artes Visuais na Universidade do Estado de Santa Catarina. Participa do grupo de pesquisa Entre Paisagens CNPq/Udesc e do programa de extensão Grupo de Estudos Estúdio de Pintura Apotheke. Tem experiência na área de pintura, desenho, gravura e design gráfico. Lattes: http:// lattes.cnpq.br/1573499434997969. Orcid: https://orcid.org/0000-0002-9113-2580. E-mail: miguelvass@gmail.com. 


\section{RESUMO}

O presente artigo tece relações entre experiência docente e estudos teóricos, com o objetivo de analisar fundamentalmente as vivências do Estágio Curricular Supervisionado I, disciplina do curso de Licenciatura em Artes Visuais da Universidade do Estado de Santa Catarina (UDESC). A atuação pedagógica da disciplina ocorreu na Educação Infantil, junto ao Núcleo de Educação Infantil Municipal (NEIM) Hassis, localizado em Florianópolis-SC. As teorias pedagógicas que influenciaram a pesquisa no estágio estão relacionadas com obras de John Dewey (1932, 1959, 1979a, 1979b) e amparadas por autores contemporâneos (CUNHA, CARVALHO), os quais promovem uma análise progressiva de algumas das teorias de Dewey em filosofia e educação.

\section{PALAVRAS-CHAVE}

John Dewey; Estágio em Artes Visuais; Educação Infantil.

\section{ABSTRACT}

This article weaves relationships between teaching experience and theoretical studies in order to fundamentally analyze the experiences of the Supervised Curricular Internship I, a discipline in the Visual Arts degree course at the State University of Santa Catarina (UDESC). The pedagogical performance resulting from the discipline took place in Early Childhood Education, at the Municipal Child Education Center (NEIM) Hassis, located in FlorianópolisSC. The pedagogical theories that influenced the research in the internship are related to works by John Dewey (1932, 1959, 1979a, 1979b) and supported by contemporary authors (CUNHA, CARVALHO), whom promote a progressive analysis of some of Dewey's theories in philosophy and education.

\section{KEY WORDS}

John Dewey; Visual Arts Internship; Child education. 


\section{Introdução}

Esta pesquisa origina-se de experiências no primeiro estágio da licenciatura em Artes Visuais, o qual aconteceu na Educação Infantil. O estágio, realizado em grupo com duas colegas estagiárias, ocorreu junto a uma turma de crianças de 3 a 4 anos de idade, no Núcleo de Educação Infantil Municipal (NEIM) Hassis, localizado em Florianópolis-SC.

A disciplina de Estágio Curricular Supervisionado $I^{1}$ do curso de Licenciatura em Artes Visuais da Universidade do Estado de Santa Catarina (UDESC) ampara os questionamentos quanto à atuação teórico/prática do professor de Artes Visuais em formação. A elaboração de proposições pedagógicas, na disciplina, não aconteceu somente pela via dos estudos teóricos, mas foram resultado de um processo que permeou conversas, estudos práticos, leituras, experimentações e invenções. As aulas da disciplina de estágio promoveram esse processo em um âmbito coletivo, delineando um espaço para pesquisa, criação e compartilhamentos.

A interação e a brincadeira caracterizam o cotidiano da infância, e são oportunidades de aprendizagens potenciais para o desenvolvimento das crianças. A Base Nacional Comum Curricular (BRASIL, 2016) estudada e discutida no decorrer da disciplina de estágio, formula uma concepção de criança como ser que observa, questiona, levanta hipóteses, constrói e se apropria de conhecimentos por meio das interações com o mundo físico e social. No entanto, a rotina dessas aprendizagens, como observado no estágio, não resulta somente de um processo de desenvolvimento natural ou espontâneo. Ao contrário, necessita de intencionalidade educativa às práticas pedagógicas na Educação Infantil, sobretudo para a faixa etária específica de 3 a 4 anos.

Porisso, durante o desenvolvimento do projeto de estágio, sentiu-se a necessidade de revisitar diversas teorias expostas ao longo da formação da Licenciatura em Artes Visuais, relacionando-as com as observações e as intervenções pedagógicas, com o intuito de compreendê-las na prática. Neste sentido, o presente artigo apresenta uma articulação entre os relatos da experiência docente de estágio na Educação Infantil e alguns aspectos dos estudos em filosofia e educação de John Dewey. $\bigcirc$ autor norte-americano foi selecionado porque é uma das bibliografias básicas do curso de licenciatura. Sua obra é revisitada até hoje, "[...] não por ser um clássico, mas porque antecipa inúmeros dilemas da condição pós-moderna." (BARBOSA, 2002, p. 10).

A intenção de rever suas teorias advém de uma necessidade teórica dos graduandos enquanto professores em formação. Durante o desenvolvimento do projeto de estágio, muitas dúvidas surgiram frente aos documentos curriculares de base, tanto regionais quanto nacionais. Nestes documentos há uma grande incidência no que concerne à Educação Infantil, de uma abordagem interativa, que respeite o contexto da criança e que atente principalmente às experiências do cotidiano.

1 A disciplina de Estágio Curricular Supervisionado I foi ministrada pela Profa. Ma. Priscila Anversa, no segundo semestre de 2019. 
Em contraponto, um dos principais questionamentos durante a disciplina de estágio foi quanto aos planejamentos das aulas de Artes Visuais não subestimarem os estudantes, mas sim os convidarem à construção de conceitos vistos frequentemente como demasiado "adultos" ou "complexos". Nas observações de estágio, pôde-se constatar que o conhecer está em ação desde cedo nas crianças. Por isso, sentiu-se a necessidade de entender como criar proposições que provoquem uma reflexão, mas que, ao mesmo tempo, não sejam descoladas da vivência cotidiana, de assuntos que sejam do interesse das crianças e de novas interações que partam de seus conhecimentos prévios.

Com estes questionamentos e anseios, algumas das teorias de John Dewey (2010) foram revisitadas, tendo em vista questões reflexivas do cotidiano das crianças, sem deixar de lado aspectos de suas experiências. Por este motivo, foram selecionadas algumas obras do autor para análise e reflexão em paralelo às observações e práticas docente de estágio, procurando entender, posteriormente, de que forma esses estudos influenciaram na prática em sala de aula.

Essas aproximações objetivam provocar reflexões sobre a prática docente e as influências que elas podem gerar nas próximas experiências de estágio. Dessa forma, acredita-se que refletir sobre a experiência de atuação em sala de aula seja fundamental para um trabalho consciente com a realidade escolar atual e coerente com os objetivos primordiais da docência em formação.

\section{O pensamento reflexivo e as crianças}

Um dos livros mais relevantes de John Dewey (1979a) sobre o pensamento reflexivo ou método da inteligência, relacionados ao contexto escolar, é o Como pensamos. Neste livro fica clara a intenção de Dewey, à época, em repensar novos caminhos para antigos problemas filosóficos, tendo como eixo o estudo de concepções dualísticas da filosofia, com o intuito de conciliá-las. São pontos centrais do livro em questão as pesquisas sobre lógica como campo de estudo da filosofia, objetivando uma melhor caracterização do conceito de pensamento reflexivo, especialmente no ambiente educativo.

Para Dewey (1979a), o pensamento reflexivo é aquele que acontece em cadeia, uma sucessão de fatos organizados de tal forma a chegar-se a determinado fim. Esse tipo de pensamento não seria apenas a expressão do fluxo da consciência ou de crenças dogmáticas (normalmente ligadas às relações afetivas com o mundo), mas também "[...] traz um propósito situado além da diversão proporcionada pelo curso de agradáveis invenções e representações mentais." (DEWEY, 1979a, p. 15-16). Sobre a possibilidade de o ato de pensar reflexivamente constituir-se para um propósito educacional, Dewey (1979a, p. 26) afirma que "[...] trazendo à mente as consequências de diferentes modalidades e linhas de ação, o pensamento faz-nos saber a quantas andamos ao agir." Dessa forma seríamos movidos pela inteligência à ação, e desta 
para uma verificação consciente de suas consequências.

Um ser irracional possui características que o impelem; ele orienta-se conforme seu estado fisiológico presente, por determinado estímulo externo. Já o ser pensante "[...] é movido por considerações remotas, por resultados, talvez, somente atingíveis anos depois." (DEWEY, 1979a, p. 26). Nesse sentido, percebe-se que, em nossa condição de seres humanos racionais, vivemos em um universo rico em significados. Agimos, na maior parte do tempo, a partir de consumações de pensamento orientadas conforme nossas necessidades e contextos sociais. Um texto pode ser um emaranhado de marcas no papel ou na tela, se não soubermos flexionar seus significados. A motivação que nos condiciona a esta "leitura" está pautada na necessidade, na resolução de uma dúvida ou problema.

Sobre a exploração dos significados, Dewey aponta a linguagem, a observação e a imaginação como categorias do pensamento. Elas não definem o pensamento em sua totalidade, mas estão circunscritas no processo reflexivo em que se pretende atingir alguma finalidade ou objetivo. Esse objetivo nem sempre é conclusivo, mas sim consumado, pois pode ser revisitado conforme as novas experiências e o desenvolvimento do conhecimento sistematizado (DEWEY, 1979a).

Sobre a linguagem, o autor a compreende enquanto parte do processo reflexivo por determinar os signos e os símbolos com os quais nos organizamos intelectualmente. Neste ponto, vale ressaltar que os símbolos da linguagem não são somente aqueles produzidos por nós mesmos, mas os próprios indícios da natureza (como nuvens escuras ser um indicativo de chuva) são passíveis de interpretações histórica e socialmente construídas.

Na escola, a linguagem é largamente difundida e explorada, principalmente como comunicação de ideias e fatos. Para Dewey (1979a), essa premissa pode tornarse um problema, uma vez que, pela comodidade por parte dos adultos, da palavra escrita, lida e falada, a linguagem pode sofrer um abuso recorrente em diversas metodologias de ensino. Com base nesta afirmação, pode-se avaliar na experiência de estágio o uso frequente da fala, especialmente em contações de histórias e narrativas sobre imagens. Assim, notou-se o quanto pode ser recorrente este "abuso" da linguagem oral, para além dos momentos em que a fala realmente é necessária. Dessa forma, percebeu-se que a exposição oral poderia ter sido enriquecida com referências visuais, táteis, olfativas etc. Isso porque as crianças respondem bem à diversos estímulos, mas também porque a simples transmissão de informações através da fala pode ser cansativa e não provocar a curiosidade dos estudantes.

Neste sentido, o autor ressalta o poder e a autonomia da observação. Para Dewey, as inferências dos alunos só devem ser respondidas ou explicadas se não houver a possibilidade de eles mesmos observarem determinado sistema e tirarem suas próprias conclusões (DEWEY, 1979a). Aqui é possível traçar uma polarização nos métodos educativos, entre observação e informação transmitida. De um lado, há uma apresentação de objetos e coisas para que os estudantes vejam, ouçam, sintam, o que irá gerar inferências, dúvidas e curiosidades espontâneas. De outro lado, teríamos uma apresentação de determinada questão e o próprio professor respondendo aos 
estudantes com uma explicação. Entende-se, a partir dessa polarização, a relevância de uma motivação coerente para o estudo de questões e assuntos no ambiente escolar, de forma que a observação gere inferências e subsídios para investigações e desejos de saber.

Todas as pessoas têm o desejo natural, irmão da curiosidade, de ampliar o círculo de relações com pessoas e coisas. $\mathrm{O}$ aviso existente em galerias de arte que obriga os visitantes a deixar guardados as bengalas e os guardachuvas no vestiário é prova evidente do fato de que, para muita gente, não basta olhar: parece-lhes que não conhecem as coisas enquanto não as tocam diretamente. É graças a esse interesse simpático que se acumulam e associam inúmeros fatos que, se não fosse isso, se conservariam esparsos, desconexos e sem utilidade para a inteligência. O resultado é mais uma organização social e estética do que conscientemente intelectual; mas provê a oportunidade natural e supre o material para as explorações conscientes intelectuais. Alguns educadores recomendaram orientar, nas escolas primárias, o estudo da natureza, não num espírito puramente analítico, mas com o fim de despertar o amor pela natureza e cultivar gostos estéticos. Outros insistem muito no trato dos animais e das plantas. Estas duas recomendações importantes originaram-se da experiência e não da teoria, mas são excelentes confirmações dos pontos de vista que acabamos de expor. (DEWEY, 1979a, p. 245, grifos nossos).

Dessa forma, vê-se que o valor da observação está enraizado na curiosidade e na experiência de pensar sobre o que se observa, em observar e tentar comunicar o que se observa, em compartilhar o que se pensa e observa. Esse processo pode promover um repertório de vivências e experiências que será usado para novas explorações do saber. Para Dewey (1979a), este repertório influencia diretamente na capacidade de inferência dos estudantes, ou seja, na habilidade de usar fatos oriundos de observações, reflexões e vivências passadas, para o bom encaminhamento de novas experiências.

As inferências são tentativas reflexivas que relacionam o que se observa com o que já se observou e o que se sabe sobre o assunto, com o intuito de resolver algumas questões ou dúvidas. Inferir é pensar em hipóteses ou possíveis soluções que, através de observações, conhecimentos e experiências passadas, pode-se verificar instantaneamente. É neste ato de pensar alternativas para as curiosidades que Dewey situa a imaginação. Ela é relevante ao pensamento para o autor, pois "[...]a imaginação não trabalha com o irreal, mas com a realização mental do que é sugerido. Seu exercício não é uma fuga para o que é puramente fantástico e ideal, mas um método de dilatar e completar o real." (DEWEY, 1979a, p. 2012).

Para o trabalho do professor em formação que atua na Educação Infantil, esta ideia é relevante pois relaciona-se intimamente com as brincadeiras e os jogos para a infância. Ela ampara diversas dúvidas quanto às orientações que colocam a brincadeira como eixo da experiência de aprendizagem dos estudantes. Neste cenário, enquanto professores de Artes Visuais em formação, pode-se observar diversos questionamentos quanto à subestimação das crianças. Isso porque, frequentemente, pode-se propor 
interações que não sejam, necessariamente, subsídios para que os estudantes desenvolvam suas capacidades de resolver dúvidas e problemas dos conteúdos escolares que os esperam na continuidade de suas formações. Do mesmo modo que, nesta continuidade dos anos escolares, a falta de interações e brincadeiras e o foco quase que exclusivo em conteúdo específicos, apenas reproduzidos sem curiosidade, podem ser cansativos e desanimadores.

Desse modo, questiona-se de que forma as proposições na Educação Infantil podem ser uma brincadeira e, ao mesmo tempo, configurar-se como uma busca ou consolidação de um conhecimento específico. Para Dewey, a brincadeira é um ato que se alimenta na sucessão dos fatos e configura-se como uma prática que trabalha com significações a todo tempo. A partir do momento em que as crianças entendem os sinais das coisas, adquirem uma capacidade representativa (DEWEY, 1979a).

Um bom exemplo aconteceu durante a experiência de observações no estágio, quando uma criança convidou os graduandos a montarem uma casa com blocos de madeira, logo outras crianças reuniram-se em torno da "casa". Cada bloco representava um cômodo, apesar de todos os blocos serem exatamente iguais. Os significados eram dados conforme a opinião da maioria, e assim a casa foi construída como em uma assembleia.

"Esta é a sala... não, está longe da cozinha, então é uma torre" , foi uma das frases expostas por uma das crianças, e anotada no diário de observação. "Esse pequeno é a cama da princesa" disse outra, e foi logo interrompida: "Não, é muito pequeno. Esse vai ser uma pequena piscina do cachorro".

Sobre a manipulação dos brinquedos como um jogo de significações, Dewey (1979a, p. 207) aponta que "[...] manipulando-os, elas [as crianças] vivem, não com as coisas naturais, mas no vasto mundo dos significados, natural e social, evocado por essas coisas." Para o autor, quando as crianças brincam (de "casinha", por exemplo) estão "[...] subordinando o presente físico ao ideal significado. Define-se e constróise, assim, um mundo de significações, uma reserva de conceitos (tão importante em toda operação intelectual)." (DEWEY, 1979a, p. 207). Ou seja, mais tarde, na vida das crianças, esses significados podem se tornar, não somente conhecimentos familiares, mas também subsídios para se agruparem, se ligarem por conexões; tornam-se repertórios para reflexões e inferências.

Contudo, esse processo não satisfaz totalmente uma intenção pedagógica, se a brincadeira for uma mera ocupação do tempo, ou se o jogo de significações não tiver um uso prático no futuro. Este uso pode configurar-se como um pensamento reflexivo completo quando houver uma ação inteligente. Ou seja, a brincadeira com intencionalidade pedagógica pode gerar subsídios para experiências e investigações de aprendizagem que serão utilizadas no futuro conforme contexto e necessidades dos estudantes.

Por este motivo, Dewey acredita que é imprescindível que os educadores aproveitem este estado de espírito da brincadeira e imaginação das crianças para pensar de que forma o conhecimento pode se apresentar, de maneira que as proposições em sala de aula possam respeitar e valorizar as experiências cotidianas 
da criança, sem deixar de lado os fatos e verdades de conceitos tidos como "adultos" ou "complexos". Esses conceitos podem ser o resultado de diversas reflexões que se iniciam na brincadeira, mas que encontram utilidade específica no empreendimento de ações inteligentes, ações movidas por necessidades, curiosidade ou pelo desejo do saber.

Dessa forma, o professor pode promover possibilidades de uma emancipação dos estudantes em seus processos de aprendizagem, o que, no caso desta pesquisa, constitui objetivo central da prática de estágio.

Partindo desta exposição de alguns aspectos do pensamento reflexivo para Dewey, em relação à educação escolar, pode-se compreender melhor os objetivos da atuação de estágio em questão. É importante frisar a influência destas teorias na conjuntura das proposições de aulas e na seleção dos conteúdos e das abordagens nas aulas de Artes Visuais na Educação Infantil. A partir desses preceitos, tenta-se, a seguir, compreender alguns conceitos dos estudos de John Dewey em relação ao planejamento e à prática docente do estágio através dos relatos de experiência.

\section{Estágio na Educação Infantil: entre teoria e prática}

Partindo do pressuposto de que os estudantes na Educação Infantil possuem subsídios para desenvolver, dentro de suas singularidades, reflexões sobre suas curiosidades nas aulas de Artes Visuais, procurou-se entender quais são os conteúdos de Arte específicos para a faixa etária de 3 a 4 anos e de que forma eles poderiam ser abordados.

O planejamento das aulas partiu inicialmente dos fundamentos do Projeto Pedagógico do NEIM Hassis. Segundo esse projeto, no trabalho com as crianças, a brincadeira "[...] deve ser tomada como eixo estruturante e estruturador das suas vivências e experiências, mediadas pelas mais variadas formas de linguagens e contextos comunicativos" (FLORIANÓPOLIS, 2015, p. 26).

Nesta abordagem, sentiu-se a necessidade de uma abertura para se pensar além das interações e brincadeiras, ou sobre como promover o conhecimento das Artes Visuais nesta paisagem pedagógica. Neste contexto, Dewey escreve um artigo em meados dos anos 30 intitulado "A criança e os programas de ensino", no qual aponta dois fatores na educação de crianças da época, mas que, no contexto atual, podem revelar-se como sendo contemporâneos: "[...] de um lado, a criança, ser que evolui, e, de outro, certas ideias, certos objetivos, certos valores adquiridos pela experiência amadurecida dos adultos." (DEWEY, 1932, p.115).

A intenção do autor é promover um entendimento de que a educação deveria contemplar esses dois componentes ao mesmo tempo, em vez de adotar apenas um deles como fórmula chave de todos os problemas da educação. Para o autor, estão equivocadas as teorias que opõem as crianças ao programa de estudos ou aquelas que diferenciam o ser individual das experiências cotidianas e coletivas. 
Cunha (1996, p. 7) expõe os estudos de John Dewey quanto a essa dualidade, fundamentando-os, quando escreve que:

Os elementos que compõe o mundo adulto estão contidos no ser infantil; os valores sociais, o raciocínio objetivo e ordenado, os saberes científica e logicamente organizados, enfim, a razão, encontra-se potencialmente presentes nas experiências da criança como ser individual, nos traços do desenvolvimento psicológico infantil. O ser individual nada mais é do que a semente do ser social; por isso não há oposição entre a liberdade da criança e os ensinamentos contidos nos programas de ensino.

A partir destas afirmativas, e tendo em mente os parâmetros curriculares nacionais e municipais, percebeu-se que o uso de propostas pedagógicas interativas se faz iminente diante da necessidade de a criança estreitar sua relação com o mundo físico e social através da brincadeira - experiência primordial da infância. Contudo, também foi imprescindível pensarmos de que forma a experiência da criança pode beneficiarse dos conteúdos de Artes Visuais, não somente como conhecimento construído histórica e socialmente, mas também como subsídio para o desenvolvimento de reflexões sobre si e sobre seus entornos, a partir dos conteúdos da disciplina de Artes Visuais.

Neste cenário, procurou-se estabelecer uma ligação estreita entre os conteúdos de Arte e a experiência da criança através de proposições que partissem de seus universos individuais e fossem ao encontro de um conhecimento "maduro". Assim, uma das primeiras aulas baseou-se em uma narrativa lúdica chamada "O monstro das cores", livro para a infância que relaciona algumas cores com emoções específicas. Nessa aula, os estudantes envolveram-se emocionalmente com a história contada e encenada, e a curiosidade quanto às cores apresentadas tornou-se latente desde o princípio.

Para melhor observação e análise das cores e das sensações que elas despertam, foram usadas caixas coloridas com as cores específicas, cada uma contendo pequenos objetos do cotidiano correspondente às cores das caixas. Nesse momento, percebeuse a capacidade analítica das crianças em seus processos de observar e reconhecer através do olhar, do tocar e do ouvir. Além disso, foi possível perceber seus desejos de comunicar o que observavam e reconheciam, através da fala, da seleção de objetos, de gestos. Alguns estudantes manifestaram seus questionamentos, inclusive, quanto à correspondência entre as cores dos objetos e suas funções.

Em um segundo momento, as crianças foram convidadas a espiar por entre aberturas de uma caixa que continha um espelho. Essa dinâmica foi essencial para as crianças perceberem suas próprias imagens como algo externo, como suas apresentações para o mundo. Neste momento, alguns estudantes manifestaram suas preferências por cores, ou apontaram algumas das cores correspondentes às roupas com as quais estavam vestidos.

Essa reflexão pode indicar o quanto estavam envolvidos na experiência e como o conteúdo de Artes Visuais já se apresentava em um uso reflexivo, externo a ele. Ou 
seja, após observarem os objetos e relacionarem estes com a narrativa ouvida e com outros objetos e situações que já observaram e vivenciaram, as crianças passaram a utilizar estes assuntos em novas questões. Quando elas viam seus reflexos no espelho, por entre as aberturas da caixa, a maioria prestou atenção às cores de suas roupas, ou às cores do fundo da sala aparente em seus reflexos. Esta atenção foi comunicada através da fala, permeada por suas imaginações: "Minha camisa tá azul escuro dentro da caixa", disse um dos estudantes. Logo depois, os que já haviam espiado por entre as aberturas da caixa, conversavam entre si sobre o que tinham visto e o que pensavam sobre aquilo. Este fato nos auxilia a perceber como a observação, a imaginação e a brincadeira estão interligadas ao pensamento e como este acontece a partir das experiências e curiosidades das crianças.

Após esse momento, conversou-se brevemente sobre nossas imagens pessoais, relacionando o espelho com nosso hábito de produzir fotografias. Citamos o uso de porta-retratos com fotografias, recorrente nas residências de famílias, o que curiosamente as crianças responderam com certo desconhecimento sobre o fato. " $\mathrm{Na}$ minha casa não tem isso, minha mãe tem foto no celular" foi a resposta de um dos estudantes, seguido por afirmativas da maioria "minha irmã e eu tiramos selfies".

A partir dessa conversa, foram apresentados alguns álbuns de família de uma das colegas graduandas do grupo de estágio. Eram fotos de família, em diversas ocasiões. Em meio as fotos, havia impressões de algumas pinturas de Frida Kahlo. As crianças mostraram-se extremamente curiosas quanto aquelas imagens. Eram fotos? De onde vinham? Quem era aquela moça?

Neste momento, pode-se introduzir alguns aspectos da vida da artista mexicana, partindo sempre dos questionamentos das crianças, seus desejos de saberes. Também pode-se explorar em conversas e compartilhamentos algumas das inferências dos estudantes sobre as imagens serem desenhos, pinturas ou fotografias, tendo em vista que as dúvidas do grupo encaminhariam a exposição dos fatos. A partir destes momentos, entendemos como a experiência da criança é permeada por seus desejos de saber e suas curiosidades. Elas manifestam-se a partir de suas próprias dúvidas e interesses, de forma espontânea.

Ao conceito de experiência, John Dewey dedicou boa parte de seus estudos. Pode-se dizer até que boa parte de sua filosofia se baseia em sua concepção de experiência.

A experiência consiste primariamente em relações ativas entre um ser humano e seu ambiente natural e social. Em alguns casos, a iniciativa parte do lado do ambiente; os esforços do ser humano sofrem certas frustrações e desvios. Em outros, o procedimento das coisas e pessoas do ambiente leva a desfecho favorável às tendências ativas do indivíduo, de modo que, afinal aquilo que o indivíduo sofre ou sente são consequências do que tentou produzir. (DEWEY, 1979b, p. 302).

autor acredita que o ser humano se diferencia de outros seres por ter a 
capacidade de guardar aspectos de experiências pelas quais passaram. Através da memória, os seres humanos gravam e recordam suas experiências. Algumas delas não possuem muitos componentes, a não ser tentativas que podem levar a acertos ou a erros, dentro de determinados contextos. Porém, em algumas dessas situações, certas experiências incitam a observação de novas paisagens, despertam a curiosidade, nos fazem refletir e analisar de um ponto a outro, de uma ação até seu resultado, sua consequência.

Carvalho (2015, p. 25) infere que esse último caso possui um valor especial. Para a autora, "o valor da experiência é mais extenso, adquirindo uma maior qualidade, sendo que pode proporcionar mudanças significativas no modo de pensar do indivíduo."

Segundo Carvalho (2015), John Dewey afirma que esse tipo de experiência pode ser considerado como "reflexiva", pois possui a capacidade de levar o ser humano a pensar sobre o que aconteceu. Nas próprias palavras de Dewey (1979b, p. 168): "[...] o estágio inicial do ato de pensar é a experiência".

Carvalho (2015) expõe que existe um princípio de continuidade entre uma experiência e outra na teoria de Dewey. Pode-se dizer que a experiência anterior nos dá subsídios para uma próxima experiência; da mesma forma, a experiência posterior pode revisitar afirmações contidas na anterior.

Dessa maneira, percebe-se que, segundo a teoria de Dewey, não existe nem a exaltação da ação nem a do pensamento, mas uma combinação entre eles. Sob essa perspectiva, é possível realizar uma correspondência entre os conceitos de experiência e pensamento, com as ideias vistas anteriormente sobre abordagens pedagógicas lúdicas e interativas, baseadas no cotidiano das crianças, e abordagens pedagógicas mais racionais, baseadas em conteúdos teóricos específicos. Vê-se claramente o quanto o autor trabalha a respeito destas sob uma ótica integradora, que não separa as abordagens; pelo contrário, procura elucidar aspectos inerentes às propostas de maneira a unificá-las em sala de aula.

É de mesma natureza os estudos de Dewey sobre brincadeira, linguagem, observação e imaginação. Nenhum destes conceitos fixa-se necessariamente como solução de um problema educacional, mas nos apresenta questionamentos para pensarmos a prática docente como proposta de desenvolvimento integral das crianças.

\section{Considerações finais}

Nas linhas anteriores, foram apresentadas reflexões sobre a prática docente de estágio na Educação Infantil. Estas reflexões foram geradas a partir das relações entre os relatos de estágio e os estudos teóricos de algumas das obras de John Dewey. Essa análise fundamentada foi importante para a compreensão da dinâmica entre 
teoria e prática pedagógica, especialmente para uma faixa etária em que o ensino das Artes Visuais pode ser cada vez mais raro, afirmando, desse modo, sua relevância e necessidade.

A partir das relações entre estudos sobre as teorias de John Dewey e dos relatos e questionamentos da atuação pedagógica do estágio, percebe-se, no decorrer desta pesquisa, um ponto central nas reflexões tecidas. Esse ponto diz respeito à relação entre abordagens de conhecimentos específicos das Artes Visuais e abordagens que valorizem e respeitem as experiências, os contextos e os cotidianos das crianças. Nesta relação, entende-se que as abordagens podem ser estudadas de modo unificado, compreendendo a interação e a brincadeira como oportunidades para reflexões sobre conhecimentos das Artes Visuais, enquanto subsídios para novas ideias e experiências.

Neste sentido, pode-se compreender, na prática pedagógica de estágio, os conceitos que permeiam o pensamento reflexivo, como expostos por Dewey. Foi possível verificá-los em contextos e tempos específicos durante as aulas de Artes Visuais, junto às crianças. Foi possível perceber esses conceitos em ação nas crianças durante nossas propostas de interações e brincadeiras, especialmente relacionados à conhecimentos específicos das Artes Visuais, por exemplo as cores, o retrato, o autorretrato, as diferenças entre linguagens artísticas.

Dessa forma, relacionando os relatos de estágio com as teorias estudadas, verificou-se que a brincadeira se interliga à imaginação, a qual depende de observações de mundo e de si mesmo, como combustível ao ato de significar. Também entra neste jogo do conhecer e do refletir a linguagem enquanto comunicação e expressão de ideias, questionamentos e hipóteses. Neste trânsito, foi possível perceber nitidamente o saber em ação nas crianças de pouca idade. Para eles, a escola é saudável e todo momento é uma nova oportunidade para descobrir coisas, brincar, inventar. Nesse clima de curiosidade, ainda sem o desconforto escolar que pode acontecer nos anos seguintes, percebe-se que as proposições pedagógicas possuem papel fundamental no desenvolvimento de posturas e atitudes emancipadoras no processo de aprendizagem. As proposições podem convidar os estudantes a observar, imaginar, brincar, compartilhar, ou podem cansá-los com respostas prontas e explicações demasiadamente teóricas.

A influência destas experiências de estágio para a formação dos graduandos foi valiosa, pois configurou um momento em que as teorias pedagógicas puderam ser abordadas na prática. Por este motivo, também são relevantes os registros e relatos durante o estágio, para que uma análise fundamentada possa ser efetuada em sua consumação.

Foi desta natureza que partiram os pressupostos desta pesquisa, embora não se pretenda resolver todas as dúvidas relacionadas à formação do professor. Esta análise representa uma forma de alinhar as ideias e as intenções pedagógicas, com estudos prévios e análises posteriores à atuação, visando reflexões significativas para práticas futuras. 
Os autores e as teorias abordados não são uma forma de exaltação ou confirmação de planos e aulas bem-sucedidas, mas configuram uma oportunidade de análise de atuação pedagógica fundamentada em teorias filosóficas. Por isso, é imensurável uma ideia de proposições ou planejamentos "certeiros", porém julga-se importante analisar de que forma as atuações se relacionam com a pesquisa e vice-versa, uma vez que também aos professores em formação cabe, em vários momentos, oportunidades de reflexões. Tais reflexões, articuladas com o desejo de saber e as curiosidades do professor, podem resultar em uma compreensão de suas próprias posturas e atitudes em sala de aula, entendendo seu comprometimento com a educação, mas também respeitando as vivências e os contextos dos estudantes.

\section{Referências}

BARBOSA, Ana Mae. John Dewey e o ensino da arte no Brasil. São Paulo: Cortez, 2001.

BRASIL. Ministério da Educação. Base Nacional Comum Curricular - BNCC. Brasília, DF: MEC, 2016.

CARVALHO, Viviane Batista. John Dewey e o trabalho pedagógico na educação infantil. Curitiba: Appris, 2015.

CUNHA, Marcus Vinicius da. Dewey e Piaget no Brasil dos anos 30. Cadernos de Pesquisa, São Paulo, n. 96, p. 5-12, maio 1996.

DEWEY, John. A criança e os programas de ensino. Educação, São Paulo, v. 7, n. 4, 1932.

DEWEY, John. Vida e Educação. Tradução de Anísio Teixeira. 5. ed. São Paulo: Nacional. 1959.

DEWEY, John. Como Pensamos, como se relaciona o pensamento reflexivo com o processo educativo: uma reexposição. Tradução: Haydée Camargo Campos. 4. ed. São Paulo: Nacional, 1979a.

DEWEY, John. Democracia e Educação. Tradução de Godofredo Rangel e Anísio Teixeira. São Paulo: Nacional, 1979b.

FLORIANÓPOLIS. Secretaria Municipal da Educação. Creche Hassis. Projeto Político Pedagógico. Florianópolis, SC: SED, 2015.

LLENAS, Anna. O monstro das cores. Lisboa: Nuvem de Letras, 2020.

SANTA CATARINA. Secretaria de Estado da Educação. Currículo base da educação infantil e do ensino fundamental. Florianópolis: SEE, 2019.

Submissão: $25 / 05 / 21$

Aceitação: 06/06/21 